Doi: https://doi.org/10.31578/jebs.v6i1.227

\title{
Effect of two Computer Instructional Modes on Secondary School Students' Achievement in Geography, in Lagos State, Nigeria.
}

\author{
Tayo Omoniyi* \\ Lucky Uzoma Nwosu** \\ Fakokunde Jubril Busuyi***
}

\begin{abstract}
There is a growing concern about secondary school students' poor performance in geography, a subject that is prerequisite for many professional pursuits. To enhance their performance in the subject, several strategies have been adopted. This study is an intervention, which investigated relative effects of computer instructional modes (computer graphics and animations computer) on secondary school students' achievement in geography. The moderator variable was mental ability. Two hypotheses were formulated and tested at 0.05 level of significance. The pre-test, post-test control group quasi-experimental design, involving $3 \times 2$ factorial matrix was adopted for the study. One hundred and four senior secondary two geography students from three secondary schools in Lagos state constituted the sample for the study, which lasted for eight weeks. Two procedural instruments (computer graphics and animation instructional packages) and two measuring instruments, namely Geography Achievement Test $r=0.79$, and Mental Ability Test $r=0.88$ were used. The data collected were analysed using Analysis of Covariance (ANCOVA). The magnitude of the students' post-test achievement scores was determined using Multiple Classification Analysis (MCA), while Scheffe post-hoc analysis was used to explain the direction and source of significant effects. Findings showed that there were significant main effects of instructional mode on the students' achievement in geography $(F(2,91)=14.414, p<0.05)$. There was no significant interaction effect of treatment and mental ability on students' achievement in geography. Consequently, it was recommended that the computer instructional modes be used alongside with conventional method in the teaching of geography.
\end{abstract}

Keywords: computer graphics, computer animation, instructional mode, achievement in geography, mental ability and geography

\section{Introduction}

The emerging pace of changes in technology require to develop and apply the $21^{\text {st }}$ century digital skills for effective utilization of the emerging technologies, particularly, enhancing academic performance. According to Bitter and Pierson (2013), technologies which are often integrated into instruction include video text, broadcast tele-text, digital video, computer simulation, interactive board, i-pad phone, computer mediated instruction, animated video, digital camera, robotics, etc.

Advancement in multimedia technology has aided the provision of realistic images in computer-based instruction through the use of video clips, computer animations and graphics. Computer graphics and computer animations are two computer-aided technologies recently being used in instructions.

\footnotetext{
* Dr. Olabisi Onabanjo University, Ago-Iwoye, Ogun State, Nigeria

** Dr. Federal College of Education (Technical), Akoka, Lagos, Nigeria.

*** Olabisi Onabanjo University, Ago-Iwoye, Ogun State, Nigeria
} 
Computer graphics which deals with generation of images with the aid of computer has become a core technology in many specialized applications, including classroom instruction. Its application in the teaching and learning process includes digital representation of non-text information such as drawings, charts or photos. Since the advent of dynamic graphic-oriented computer, animation, which is a form of pictorial representation, has widely featured in technology-based learning process. Musa, Ziatdinov and Griffiths (2013) consider it as one of the most prominent applications of technology-based teaching and learning in the last two decades. It involves computer generation of motion pictures and simulations, a process for generating animated images digitally. The increased use of computer animations in technology-driven learning environment has led to its potentials at enhancing students' performance being variously investigated.

Hamzat, Bello and Abimbola (2017) investigated the effects of computer animation instructional package on secondary school students' achievement in practical biology in llorin, Nigeria. A quasi-experimental study used Biology Practical Achievement Test (BPAT) for data collection and Computer Animation Instructional Package (CAIP) as the treatment instrument. The study concluded that CAIP significantly improved students' achievement in practical biology.

Gambari, Falode and Adegbenro (2014) also examined the effectiveness of computer animation and geometry instructional model on mathematics achievement and retention. Those junior secondary school students who were taught geometry using computer animation performed significantly better in post-test and retention test than their counterparts taught geometry using instructional model and conventional method respectively.

Yisa and Ojiaku (2016) examined the effectiveness of computer animation on a progressive learning achievement of secondary school biology students in Niger state, Nigeria. A computer animation instructional package (CAIP) was developed to test the progressive performance of the students, from Senior Secondary School one to senior secondary school three. The findings indicated that the experimental group (CAIP) performed significantly better than the control group taught using the conventional teaching method.

In another study reported from Erzurum, Turkey, Gokhan (2013) investigated the effects of computer animation technique on students' comprehension of the "solar system and beyond" unit in science and technology course. The sample consisted of 60 seventh grade students, during the 2011-2012 academic session. The experimental group was given lectures using computer animation technique (CAT), involving power point presentations and videos. The control group was taught using the traditional teaching method (TTM). According to the findings, CAT was more effective than TTM in terms of enhancing students' achievement. The difference between the two groups was found statistically significant.

Inuwa (2015) investigated the impact of graphics on academic performance of junior secondary school students in social studies in Jigawa State, Nigeria. The quasi-experimental study, which utilized Graphics Media Learning Package (GMLP) as treatment instrument for the experimental group reported that there was a significant difference in the mean scores of experimental and control groups, in favour of the experimental group. Chi-Hui (2002) also reported a study on the effects of computer graphics types and epistemological beliefs on students' learning of mathematical concepts. The study had three different computer graphics treatments: computer statics graphics, computer animation and computer video. These findings, however, indicated that there were no significant main effects and interaction between students' first time learning beliefs, while significant main effect was found in the different computer graphics types.

The potentials of these computer-driven technologies to enhance students' performance has been widely investigated, particularly in the sciences and technology. Subjects such as geography that require concrete illustrations of its concepts need to explore the potential of computer graphics and animation in teaching and learning. Studies have shown that many students dread 
geography as a school subject, due to its perceived wide coverage and difficulty, especially map reading (Nwosu, 2019). This view has been confirmed by the West African Examination Council (WAEC) Examiner's Report (2016) which noted that students found map reading relatively difficult to answer. The report indicated that many students were unable to interpret the given topographical map accurately and couldn't identify features as required by questions on map reading and interpretation.

Zhu and Grabwski (2006) observed that most students have difficulty in mastering most concepts in map reading and consequently suggested the use of computer static graphics and web-based animation in the teaching and learning of geography.

The Cognitive Theory of Multimedia Learning (CTML) is germane to this study. The theory was originated by Richard Mayer (2009), who states that people learn more deeply from words and pictures than from words alone. CTML can be explained as a technology-centred approach that focuses on the use of technologies on the nature of the human cognitive system and instruction. It advocates the presentation of an instructional message to learners through two main formats of words and pictures. Words include speech and printed text, whereas pictures include static graphics (such as illustrations or photos) and dynamic graphics (such as animations or video). CTML involves the presentation of concepts, using both words and pictures with the intention of promoting learning. It rests on the premise that learners can better understand a concept when it is presented in words and pictures than when it is presented in words alone.

The cognitive theory of multi-media learning has definite implications on the use of computer graphic and animation instructional modes in the teaching-learning process. Computer graphics and animation enhance learning through verbal and pictorial presentation of concepts to be learned. Computer instructional modes may help students to understand and remember the content to be learnt by facilitating the dual coding (words and pictures) of information, as emphasised by the theory that concepts are better taught when presented in both verbal and visual cues. Computer animation and graphics combine both visual and verbal knowledge that may enhance the storage of information in the long-term memory to facilitate encoding and retrieval process of what is learnt.

\section{Objective of the Study}

The objective of the study was to investigate the effects of computer Graphics and Animation instructional modes on students' learning achievement in geography.

\section{Statement of the Problem}

Geography is an essential requirement for many fields of study or professions, including geology, quantity survey, medicine, architecture, cartography, regional planning, and aeronautics just to mention a few. Despite the relevance of geography to these professions, students find the concept of map reading and interpretation difficult, and teachers also find map reading and interpretation difficult to teach. One of the main factors adduced for this, is non-usage of computer-mediated technology. This study, therefore, seeks to determine possible effects of two computer instructional modes (graphics and animation) on secondary school students' achievement in map reading as a component of geography.

\section{Hypotheses}

The following null hypotheses guided the study:

$\mathrm{H}_{01}$ : There are no significant main effects of instructional modes (computer graphics, computer animation and conventional instructional modes) on students' achievements in geography. 
$\mathrm{H}_{02}$ : There is no significant interaction effect of instructional mode and mental ability on students' achievements in geography.

$\mathrm{H}_{03}$ : There is no significant interaction effect of instructional mode and gender on students' achievements in geography.

\section{Research Design}

This study adopted the pre-test - post-test, quasi-experimental design, involving a $3 \times 2$ factorial matrix. This represents three levels of instructional modes which are, the graphics instructional mode (experimental group 1), animation instructional mode (experimental group 2) and the conventional instructional mode (group 3 - control group) at two levels of mental ability (high and low). The instructional modes are the independent variables in this study, while achievement in geography is the dependent variable. The moderator variable is mental ability.

\section{Sample and Sampling Technique}

The total sample for the study comprised one hundred and four (104) senior secondary school II (SSII) geography students from the selected schools in Lagos state, Nigeria. This comprised of thirty one (31) students in experimental group 1(computer graphics mode), thirty eight (38) students in experimental group 2 (computer animation mode) and thirty five (35) students in the control group. The SS11 students of geography constituted samples for this study, because they were not preparing for senior secondary school examination and this provided sufficient time to carry out the study. Furthermore, they have been exposed to geography the concepts in SS1.

Three education districts were also selected through simple random sampling technique and one school from each of the three education districts using purposive random sampling technique. The selected schools were randomly allocated to treatment or control groups using ballot procedure.

The instruments used for this study were Computer Graphics Instructional Mode (CGIM) Learning Package in Geography, Computer Animation Instructional Mode (CAIM) Learning Package in Geography, Geography Achievement Test (GAT), and Mental Ability Test (MAT.

The learning packages (CGIM \& CAIM) were developed by the researcher, with the assistance of a computer graphics programmer. They were administered on the experimental groups (1\&2). The contents were based on the following map reading topics: methods of relief presentation, interpretation of physical features, interpretation of drainage patterns and features, drawing of cross-section (profile) and inter-visibility. The subject learning packages were validated by the experts in instructional and geography teachers. The teacher taught the students of the conventional (control) group, using basic instructional design media such as diagrams, maps, charts, models and chalk/marker boards.

The Geography Achievement Test (GAT) which consists of thirty (30) multiple-choice items was used to assess students' achievement in geography. The items were adopted from past senior secondary certificate examination (SSCE) questions that correspond to the selected topics in map reading. Each item had five options (A-E), which include one correct answer and four distractors. The 70 items were administered to fifty (50) SS2 students not participating in the main study for the purpose of item analysis and 30 items that discriminated and distracted satisfactorily were eventually picked for the study. 
The Mental Ability Test (MAT) is a 30-item adopted from the Australian Council for Education Research (ACER) standardised Mental Ability Test. It was used to classify the students into high and low ability levels. Those participates who scored below the mean ability score of all were grouped as low mental ability, whereas those above the mean score were grouped as high mental ability students. MAT has undergone several field validation and modifications (Aremu and Sangodoyin, 2010). The instrument was trial-tested, and the reliability coefficient of the instrument using Cronbach alpha coefficient was 0.89.

The study lasted eight (8) weeks and the sequence included: training and orientation of participating teachers, conducting pre-tests (GAT was administered as pre-test), and at the end of the treatment, items of Geography Achievement Test (GAT) administered as post- test.

The two hypotheses formulated were tested using the Analysis of Covariance (ANCOVA) with pre-test scores as covariates. The analysis was done at the 0.05 level of significance. The accompanying Multiple Classification Analysis (MCA) was used to determine the magnitudes of the post-test of achievement and attitude scores, while the Scheffe Post-hoc analysis used to explain the source and direction of obtained significant effects.

\section{Results and Discussion}

\section{Test of Hypothesis One}

H01: There is no significant main effect of treatment (instructional mode) on students' achievement in geography.

Table 1: Summary of Analysis of Covariance of Students' Achievement Scores According to Treatment (Instructional Modes), Mental Ability and Gender

\begin{tabular}{|l|l|l|l|l|l|}
\hline Source of Variation & Sum of Squares & Df & Mean Square & F & Sig. of F \\
\hline Main Effects & 726.956 & 1 & 726.956 & 117.181 & .000 \\
\hline Covariates (pre-test) & 573.156 & 1 & 573.156 & 92.389 & .000 \\
\hline Treatment (Inst. Mode) & 178.847 & 2 & 89.424 & 14.414 & $.000^{*}$ \\
\hline Mental Ability (MA) & 223.985 & 1 & 223.985 & 36.105 & $.000^{*}$ \\
\hline $\mathbf{2}$ Way Interaction & & & & & \\
\hline Treatment * M. Ability & 6.900 & 2 & 3.450 & .556 & .575 \\
\hline Explained & 2307.923 & 12 & 192.327 & 31.002 & .000 \\
\hline Residual & 564.539 & 91 & 6.204 & & \\
\hline Corrected Total & 2872.462 & 103 & & & \\
\hline
\end{tabular}

* Denote significant $\mathrm{F}$ at 0.05 level

R Squared $=0.803 \quad($ Adjusted R Squared $=0.778)$

Table 1 shows the result of the main effect of instructional mode (as treatment) on the students' achievement scores in Geography. The table shows a significant main effect of instructional mode on the students' achievement scores $(F(2,91)=$ $14.414, \mathrm{P}<0.05)$. This outcome implies that there is a significant difference in the post-test mean achievement scores of the students exposed to the three levels of instructional mode. Therefore, the null hypothesis one which states that there is no significant main effect of treatment on students' achievement in geography is rejected.

The results of the Multiple Classification Analysis (MCA) presented in Table 2, show the magnitude of the post-test mean achievement scores of the participants according to instructional mode. This is to determine the best of the three (tow experimental and one control) groups in terms of the magnitudes of post-test mean scores recorded.

Table 2: MCA of Students' Achievement Scores According to Treatment (Instructional Modes) and Mental Ability 
Grand Mean = 18.629

\begin{tabular}{|l|l|l|l|l|l|}
\hline $\begin{array}{l}\text { Variable + Category } \\
\text { Instructional Mode }\end{array}$ & $\mathbf{N}$ & $\begin{array}{l}\text { Unadjusted } \\
\text { Deviation }\end{array}$ & Eta & $\begin{array}{l}\text { Adjusted for Independent + } \\
\text { Covariates }\end{array}$ & Beta \\
\hline CGIM & 31 & 1.269 & & 1.318 & \\
CAIM & 38 & 0.611 & .248 & -1.566 & .225 \\
Conv. Method & 35 & -1.788 & & & \\
\hline Mental Ability & & & & 3.626 & .717 \\
\hline 1. High & 54 & 3.677 & .727 & -3.916 & .528 \\
2. Low & 50 & -3.971 & & & .763 \\
\hline Multiple R Squared & & & & & \\
\hline Multiple R & & & & \\
\hline
\end{tabular}

The results in Table 2 show the magnitude of the adjusted post-test mean achievement scores of the students exposed to the three levels of instructional modes. The MCA shows that with a grand mean of 18.629 , the students exposed to the computer graphics instructional mode (CGIM) recorded the highest adjusted post-test mean achievement score of 19.947 (i.e. $18.629+$ 1.318). The students exposed to computer animation instructional mode (CAIM) recorded the next higher adjusted post-test mean achievement score of 18.996 (i.e. $18.629+0.367$ ), while the students exposed to the conventional method recorded the lowest adjusted post-test mean achievement score of 16.841 (i.e. 18.629 - 1.566). This outcome, therefore, shows that the treatment computer graphics instructional mode with the highest post-test mean achievement score, appears to be the best of the three modes for improving the students' achievement in geography.

In order to trace the source of the significant difference obtained in Table 1with respect to the main effect of treatment, the Scheffe post-hoc analysis was carried out and the summary is presented in table 3.

Table 3: Scheffe Pair-wise Comparisons of Achievement Scores on Instructional Mode

\begin{tabular}{|l|l|l|l|l|}
\hline Mean & Instructional Mode & CGIM & CAIM & Conventional Method \\
\hline 19.903 & CGIM & & & ${ }^{*}$ \\
\hline 19.291 & CAIM & & & ${ }^{*}$ \\
\hline 16.694 & Conventional Method & $*$ & $*$ & \\
\hline
\end{tabular}

* denotes pairs of groups that are significantly different at $P<0.05$

The results in Table 3 show the source of the obtained significant difference in the main effect of the instructional mode. There was a significant difference in the post-test mean achievement scores of the students exposed to the pair of computer graphics instructional mode (CGIM) and conventional method (CMT), on the one hand, and the pair of computer animation instructional mode (CAIM) and conventional method on the other, at the 0.05 level of significance. However, there was no significant difference between the post-test mean achievement scores of the students exposed to the other possible pair viz CGIM and CAIM. Hence, the significant difference between the pairs of CGIM and CMT as well as CAIM and CMT are responsible for the significant difference recorded with respect to hypothesis one.

\section{Test of Hypothesis Two}

$\mathbf{H}_{\mathbf{0 7}}$ : There is no significant interaction effect of treatment and mental ability on students' achievement in geography.

Table 2 shows the result of the 2-way interaction effect of instructional mode (treatment) and mental ability on the students' achievement scores in geography. The results show no significant interaction effect of instructional mode and mental ability on 
the students' post-test achievement scores in geography $(\mathrm{F}(2,91)=.556, \mathrm{P}>0.05)$. This outcome shows that there is no significant difference in the post-test mean achievement scores in geography of the students having a high and low mental ability levels and exposed to the three levels of treatment (instructional modes) used in the study. Hence, the null hypothesis two which states that there is no significant interaction effect of treatment and mental ability on students' achievement in geography is retained.

\section{Discussion of Findings}

The results of hypothesis 1 show that there is a significant effect of treatment on students' achievement in geography (map reading). The findings also reveal that all three groups of students exposed to the three levels of instructional modes have some improvement in achievement scores. It further indicates that the two experimental groups (CGIM and CAIM) improving the achievement more than the control group instructed by conventional methods. At the same time, the results show that the students exposed to computer graphics instructional mode recorded the highest adjusted post-test mean achievement score, followed by those exposed to computer animation instructional mode; while the conventional method group recorded the least adjusted post-test achievement score. This outcome suggests that the computer graphics instructional mode appears to be the best of the three modes for improving achievement in map reading.

The finding on the effectiveness of computer animation instructional package in agreement with the studies of Hamzat, Bello and Abimbola (2017), which reported that computer instructional package significantly improved students' achievement in practical biology. It is also in accord with the findings of Gambari, Falode and Adegbenro (2014), which also reported that students taught geometry using computer animation performed significantly better in post-test and retention test than their counterparts taught using the conventional method. The findings agree with the report of a study by Yisa and Ojiaku (2016), which states that the students applying computer animation instructional package (CAIP) performed significantly better than the students taught by conventional methods in a study on performance of secondary school biology students. The same superiority in performance of computer animation was reported by Gokman (2013).

Computer graphics has also been variously reported by Inuwa (2015) and Chi-Hui (2002) as being significantly more effective in improving the academic performance of students than the conventional teaching method.

While both computer instructional modes in this study demonstrated a greater effect in achievement than the conventional method, computer graphics was found to be more effective than computer animation. This result is not in agreement with the study of Aremu and Sangodoyin (2010), which states that computer animation mode recorded a higher achievement score than computer graphics in biology. The higher achievement mean score of computer graphics over computer animation may be ascribed to the fact that the subject matter of map reading centres mainly on the identification and interpretation of features in topographical map.

According to Zhu and Grabwski (2006), animation mode is more effective in teaching process related topics, while graphic mode is good in teaching identification of features and objects. They added that both modes should be used to complement each other. This means that computer animation may be more effective than computer graphics in teaching the formation of landforms and movement of ocean currents in physical geography. This is a possibility that may (and should) be verified empirically.

The results of the two-way interaction effect of instructional mode and mental ability on the students' achievement scores in geography showed no significant effect with $(F(2.91)=0.556, P>0.05)$. This outcome means that the three instructional modes 
(CGIM, CAIM \& CM) have the same effect across both levels of mental ability (high and low) with respect to achievement in geography. Thus, null hypothesis 3 is retained. This is in agreement with the findings of Oloyede $\&$ Bamidele (2002) that both the high mental ability and low mental ability students exposed to computer mediated instruction showed no significant difference in their achievement. However, this is contrary to the findings of Egunjobi (2002) that high mental ability students performed significantly better than low mental students when exposed to computer instructional modes in the study of Geography.

\section{Conclusion}

This study investigated the relative effects of computer graphics instructional mode and computer animation instructional mode on secondary school students' achievement in geography (map reading). Educational technologists have tried to evolve innovative ways of improving instructional presentation. Consequently, researches focused on comparison between technology-mediated instructional and non-mediated instruction (conventional method). The findings of the study showed a significant mean effect of the instructional mode on the students' learning outcomes in geography. It also revealed that all three groups (including the control group) had improvement in learning outcomes after instructions. This suggests that all the modes have the potency to improve learning in geography. Therefore, it may be desirable to blend the conventional method of instruction with computer graphics and computer animation instructional modes to promote effective learning outcomes in geography, especially while dealing with map reading. Computer should not a substitute, but an aid for quality teaching and as such, there is the need to systematically utilise computer to enhance beneficial teaching and stimulate maximum learning.

\section{Recommendations}

Based on the findings of this study, the following recommendations are made:

- Computer graphics and computer animation should be used alongside the conventional method in the teaching and learning of geography in secondary schools. This is recommended, since all the instructional modes proved to be effective in the post-test achievement.

- Geography teachers should be trained on the development and utilization of computer graphics and computer animation learning packages. This may be in form of practical oriented in-service workshops to integrate this technology into the secondary school geography curriculum. It is important for geography teachers to have more access to computer for instruction and development of learning packages.

- School administrators should build infrastructures and provide materials necessary for the effective use of the computer instructional modes. It was observed during the study that some schools do not have enough functional computers for an intact class. 


\section{References.}

Aremu, A. \& Sangodoyin, A. (2010). Computer animation and the academic achievement of Nigerian senior secondary school students in biology. Journal Research Center of Education Technology, 6, 148-161.

Bitter, G. G. \& Pierson, E. M. (2017). Using Technology in the Classroom. Boston: Allyn \& Bacon.

Chi-Hui, L. (2002). Effect of computer graphics types and epistemological beliefs on students' learning of mathematical concepts. Journal of Educational Computing Research, 27 (3), 265-274.

Gokhan, A. (2013). Effect of computer animation technique on students' comprehension of the "solar system and beyond" unit in the Science and Technology course. Mexlana International Journal of Education (MIJE), 3 (1), 40-46.

Gambari, A.I, Falode, C.O., \& Adegbenro, D.A. (2014). Effectiveness of computer animation and geographical instructional model on mathematics achievement and retention among junior secondary school students. European Journal of Science and Mathematics Education, 2 (2), 127-146.

Hamzat, A., Bello, G., \& Abimbola, I.O. (2017). Effect of computer animation instructional package on students' achievement in practical biology. Cypriot Journal of Educational Sciences, 12 (4) 218-227.

Inuwa, F. (2015). Impact of Graphics on Academic Performance of Junior Secondary School Students in Social Studies in Jigawa State, Nigeria. An M. Ed. thesis. Zaria, Nigeria: Ahmadu Bello University.

Mayer, R.E. (2009). Multimedia Learning. London: Cambridge University Press.

Musa, S., Ziatdinor, R, \& Griffiths, C. (2013). Introduction to Computer Animation and its possible Educational Applications. In Gallova. M, Guncaga, J., Chanasova, Z., \& Chovanova, M.M (Eds). New Challenges in Education, Retrospection of History of Education to the Future in Interdisciplinary Dialogue among Didactics of Various School subjects. (7 ${ }^{\text {st }}$ Ed.) p. $177-205$. Ruzomberok, Slovakia: Verbum-Vydavatestvo Katolicke University.

Nwosu, L.O. (2019). Effects of two computer instructional modes on secondary school students' learning outcomes in geography in Lagos State, Nigeria. Thesis. Ago-Iwoye, Nigeria: Olabisi Onabanjo University,

Oloyede, O.E. \& Bamidele, F.E. (2012). Effectiveness of computer assisted instruction on the performance of students in practical chemistry. Journal of Theory and Research of Education, 7 (1), 52-59.

West African Examination Council - WAEC (2016). The West African Senior Secondary School Certificate Examination May' Chief Examiner's Reports. Lagos: WAEC.

Yisa. N.C \& Ojiaku, F.C. (2016). Effectiveness of computer animation on a progressive learning achievement of secondary school biology students in Niger state, Nigeria. International Journal of Education and Evaluation, 2 (4), 72-81.

Zhu, I. \& Grabwski, B.L. (2006). Web-based animation or static graphic: Is the extra cost of animation worth it? Journal of Educational Multimedia and Hypermedia, 15(3), 329-347. 